\title{
Wide-line NMR and DSC studies on intrinsically disordered p53 transactivation domain and its helically pre-structured segment
}

\author{
Peter Tompa ${ }^{1, \#}$, Kyou-Hoon Han ${ }^{2,3, \#, *}$, Mónika Bokor ${ }^{4}$, Pawel Kamasa ${ }^{4}$, Ágnes Tantos ${ }^{1}$, Beáta Fritz ${ }^{1}$, Do-Hyoung Kim², \\ Chewook Lee ${ }^{2}$, Tamás Verebélyi ${ }^{4}$ E Kálmán Tompa, ${ }^{4}$ * \\ ${ }^{1}$ Institute of Enzymology, Research Center for Natural Sciences, Hungarian Academy of Sciences, Budapest 1117, Hungary, ${ }^{2}$ Genome \\ Editing Research Center, Division of Biomedical Science, Korea Research Institute of Bioscience and Biotechnology (KRIBB), Daejeon \\ $34141,{ }^{3}$ Department of Nano \& Bioinformatics, University of Science and Technology (UST), Daejeon 34113, Korea, ${ }^{4}$ Institute for Solid \\ State Physics and Optics, Wigner Research Centre for Physics, Hungarian Academy of Sciences, Budapest H-1525, Hungary
}

\begin{abstract}
Wide-line ${ }^{1} \mathrm{H}$ NMR intensity and differential scanning calorimetry measurements were carried out on the intrinsically disordered 73-residue full transactivation domain (TAD) of the p53 tumor suppressor protein and two peptides: one a wild type p53 TAD peptide with a helix pre-structuring property, and a mutant peptide with a disabled helix-forming propensity. Measurements were carried out in order to characterize their water and ion binding characteristics. By quantifying the number of hydrate water molecules, we provide a microscopic description for the interactions of water with a wild-type p53 TAD and two p53 TAD peptides. The results provide direct evidence that intrinsically disordered proteins (IDPs) and a less structured peptide not only have a higher hydration capacity than globular proteins, but are also able to bind a larger amount of charged solute ions. [BMB Reports 2016; 49(9): 497-501]
\end{abstract}

\section{INTRODUCTION}

IDPs (intrinsically disordered proteins) are highly peculiar proteins that are devoid of tertiary structures yet are functional (1-3). These proteins are a focus of intense research over the last decade due to their unorthodox structure-function

*Corresponding authors. Kyou-Hoon Han, Tel: +82-42-860-4251; Fax: +82-42-860-4259; E-mail: khhan600@kribb.re.kr, Kálmán Tompa, Tel: +36-1-392-2213; Fax: +36-1-392-2215; E-mail: tompa.kalman@ wigner.mta.hu

${ }^{\#}$ These authors contributed equally to this work.

http://dx.doi.org/10.5483/BMBRep.2016.49.9.037

Received 24 February 2016, Revised 18 March 2016, Accepted 26 March 2016

Keywords: Differential Scanning Calorimetry (DSC), Hydration, p53 Transactivation Domain (p53TAD), Pre-Structured Motif (PreSMo), Wide-line NMR behavior. By definition, IDPs have to contain at least one intrinsically disordered region (IDR) consisting of more than 40 amino acid residues, that do not form a globular structure. The prime significance of IDPs lies in the observation that they are associated with several important diseases such as cancers, mad cow disease, viral diseases, and neurodegenerative diseases to name a few $(1,3)$. Several disorder predictions using different bioinformatics programs have provided a consensus that IDPs occupy more than $30 \%$ of the entire protein kingdom $(4,5)$.

The high-resolution heteronuclear multidimensional NMR spectroscopy, which has developed well by the mid-1990s, is a robust tool that provides us with quantitative atomicresolution structural knowledge on proteins and many other biomolecules $(6,7)$. During the last two decades, dozens of heteronuclear NMR structural investigations were undertaken on IDPs/IDRs. They revealed an interesting fact that most (at least $70 \%$ ) IDPs are not just "unstructured", as one naively envisioned at the dawn of IDP research (1). It was especially noted that IDPs may be fully unfolded in a tertiary sense, but may not be fully unstructured in a secondary sense. For example, a completely unstructured (CU) state of an IDP represents a structural state where an IDP is completely devoid of structures, both in a tertiary and a secondary sense. On the other hand, a mostly unstructured (MU) state is a structural state of an IDP where a protein is fully unfolded only in a tertiary sense, but contains transient secondary structural elements. Transient local secondary structural elements observed in target-unbound MU type IDPs "pre-exist" (8) or "pre-form" (9), and are primed for target binding. These elements are recently renamed more appropriately as pre-structured motifs (PreSMos). PreSMos are of critical importance for our understanding of IDP-target mechanism (1), since target binding of IDPs is expected to involve initial recognition of a PreSMo by a target followed by further structural tightening of the PreSMo into a stable secondary structure, e.g. a helix, rather than going through a full induced 
fit starting from a random coil.

Apart from high-resolution NMR, we wanted to explore other experimental techniques that could distinguish the CU-type IDPs versus the MU-type IDPs. Previously, we used two independent methods: the wide-line NMR and differential scanning calorimetry (DSC). Our results show that the combination of the two methods is an efficient tool for differentiating IDPs against globular proteins (10-12). To further evaluate if these techniques would be able to distinguish the $\mathrm{CU}$ and the MU states of IDPs, we carried out wide-line NMR and DSC measurements on a wild-type full 73-residue p53 TAD that contains three PreSMos, one helix (residues 18-26) and two turns (residues 40-45 and residues 49-54, respectively) (8), as well as two peptides - one wild-type helix-forming peptide, and the other with helix-breaking mutations $(19 \mathrm{~F} \rightarrow$ Ala, $22 \mathrm{~L} \rightarrow$ Ala, 23W $\rightarrow$ Ala, and $25 \mathrm{~L} \rightarrow$ Ala). Our aim was to gain information on the behavior of water molecules in the solutions of a wild type full p53 TAD and two "helix" peptides with and without helix-forming propensity, and to characterize their structural features in terms of bound water fraction.

We applied the terminology proposed by Cooke and Kuntz (13) for bound water nomination: water molecules which are in the vicinity of and interact with macromolecular surfaces and have properties that are detectably different from those of the medium, were referred to as "bound water", and the remaining water as "bulk water". By the term "unfrozen water", we denote the actual fraction of water molecules in a mobile state at a given temperature. The unfrozen water can therefore refer to a phase composed of either bound water molecules only, or bound plus bulk water molecules. Here, we aim to characterize the hydration/solvation properties of the intrinsically disordered full p53 TAD and its peptides using proton wide-line NMR intensity and DSC measurements, by taking the results of a globular protein (BSA) as a reference. Our results confirm that p53 TAD and a less structured peptide have a higher hydration potential, and also reveal an unexpected fact that p53 TAD has a large capacity and broad specificity for ion binding.

\section{RESULTS}

Wide-line ${ }^{1} \mathrm{H}-\mathrm{NMR}$ measurements gives information about the hydration of a protein, which relates to the level of order of a disordered protein (10-12). The wide-line ${ }^{1} \mathrm{H}-\mathrm{NMR}$ signal intensity is the measure of the number of mobile protons, which is equivalent to the number of mobile water molecules, expressed as hydration ( $h$, gram water/gram protein) (see Fig. 1 for example). The slopes of hydration vs. temperature curves give a quantitative parameter characteristic of the energetic heterogeneity of protein-water interactions. The steeply the hydration curve changes with temperature, the wider are the energy distributions of these interactions. The interactions of the IDPs with water molecules are characterized with broad energy distributions; however, these energies fall in a much narrower range for globular proteins $(14,15)$.

\section{Full p53 TAD dissolved in water, wide-line ${ }^{1} \mathrm{H}$ NMR}

The hydration curve or melting diagram measured for the full p53 TAD dissolved in water (Fig. 1A) shows a thermal trend, and hydration values that are typical of the IDPs (see e.g. refs. 6 , 8). Mobile hydrogen atoms, i.e. the reorienting water molecules, are first detected at $-43^{\circ} \mathrm{C}$, which is a much higher temperature than the $-60^{\circ} \mathrm{C}$ for the globular BSA (Fig. $1 \mathrm{~A})$, even though the amount of this mobile water for the full p53 TAD $(h=0.45)$ was similar to the hydration measured for the globular protein BSA $\left(h=0.50\right.$ at $\left.-44^{\circ} \mathrm{C}\right)$. In contrast to the quasi constant hydration behavior of $\mathrm{BSA}$, the hydration curve for the full p53 TAD shows continuously growing number of mobile water molecules with increasing
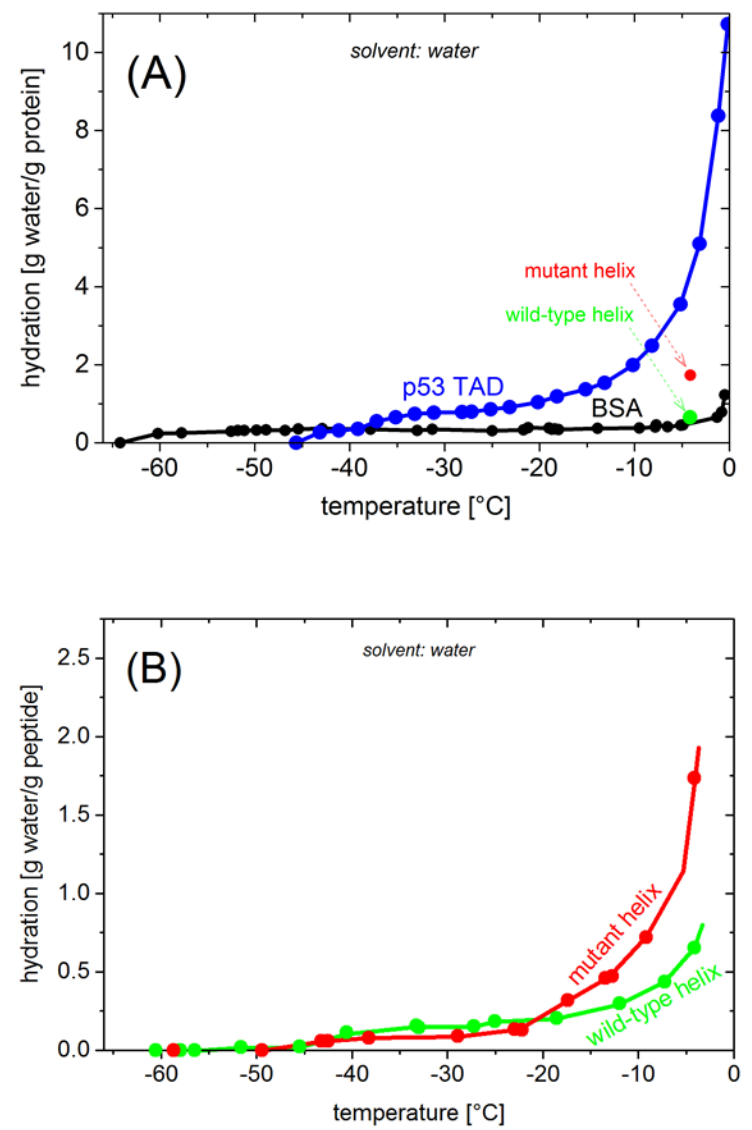

Fig. 1. Hydration measured by the ${ }^{1} \mathrm{H}-\mathrm{NMR}$ signal intensities of the mobile water for (A) $50 \mathrm{mg} / \mathrm{ml}$ p53 TAD (blue circles) and $50 \mathrm{mg} / \mathrm{ml} \mathrm{BSA}$ (black circles) dissolved in water. The $T=-4^{\circ} \mathrm{C}$ data for the helices (green and red circles) are the same as in graph (B). (B) $30 \mathrm{mg} / \mathrm{ml}$ p53 TAD helix (green circles) and 30 $\mathrm{mg} / \mathrm{ml}$ mutant helix (red circles) dissolved in water. The lines are guides to the eye. 
temperature, between $-60^{\circ} \mathrm{C}$ and $-5^{\circ} \mathrm{C}$. The low-temperature step in the hydration curve appears when detectable molecular motion becomes active (Fig. 1A). The lower this 'melting' temperature, the weaker is the interaction between the water molecules and the protein, compared to the water-water interaction in the bulk solvent (7). Thus, our results indicate that water-protein interaction for water-BSA is weaker than for water-p53 TAD.

\section{Helices dissolved in water, wide-line ${ }^{\mathbf{1}} \mathrm{H}$ NMR}

The helix forming peptide (15-29) and its mutant (F19A, L22A, W23A, L26A) bind lesser water (Fig. 1B) than the full p53 TAD; their hydrations are about the third or a half, respectively, of the hydration of the full p53 TAD (Fig. 1A). For comparison, the hydration values measured for the peptides at $-5^{\circ} \mathrm{C}$ are shown as filled circles (red and green) in Fig. 1A. The bound water molecules of both peptides start to rotate at $-43^{\circ} \mathrm{C}$, which is the same temperature value where the full p53 TAD begins to rotate. The melting diagrams of both peptides are very similar up to $-20^{\circ} \mathrm{C}$. Above $-20^{\circ} \mathrm{C}$, the hydration of the wild type peptide increases gradually with increasing temperature at a considerably slower pace than that of the mutant peptide. The hydration curve of the mutant peptide shows a very intensively enhancing region up to $0^{\circ} \mathrm{C}$.

\section{Full p53 TAD dissolved in buffer of $150 \mathrm{mM} \mathrm{NaCl}$, wide-line ${ }^{1} \mathrm{H}$ NMR}

In general, the hydration of the proteins dissolved in buffer solution is much higher than that in pure water as solvent (compare the ordinates in Figs. 1 \& 2). The hydration curve of the full p53 TAD in buffer shows a 'hydration water melting' at the same temperature similar to the one measured in salt-free solution. In Fig. 2A, the hydration values of the full p53 TAD measured between $-43^{\circ} \mathrm{C}$ and $-28^{\circ} \mathrm{C}$ are nearly the same as that of BSA (the curves are essentially superimposable), although it becomes much greater at higher temperatures, i.e. above $-28^{\circ} \mathrm{C}$, than that of $\mathrm{BSA}$. This result suggests that $\mathrm{p} 53$ TAD has two temperature regions $\left(-43^{\circ} \mathrm{C}\right.$ and $-28^{\circ} \mathrm{C}$, and above $-28^{\circ} \mathrm{C}$ up to $0^{\circ} \mathrm{C}$ ) which interact with the solute ions. The lower-temperature melting diagram for the range of $-43^{\circ} \mathrm{C}$ and $-28^{\circ} \mathrm{C}$ reflects a salt binding behavior similar to the globular reference protein $\mathrm{BSA}$, while the highertemperature diagram for the range $>-28^{\circ} \mathrm{C}$ up to $0^{\circ} \mathrm{C}$ indicates a salt binding behavior like an IDP.

\section{Helices dissolved in buffer of $150 \mathrm{mM} \mathrm{NaCl}$, wide-line ${ }^{1} \mathrm{H}$ NMR}

The hydration curves in the salty buffer solution, both for the wild type and the mutant peptide, are essentially very similar to each other (the melting curves are superimposable). However, measurable differences are visible in the temperature range of $-27^{\circ} \mathrm{C}--5^{\circ} \mathrm{C}$ (Fig. 2B).

\section{Differential scanning calorimetry}

We have previously demonstrated that DSC experiments can provide information on the protein-ion interactions or the salt binding properties of biopolymers (17). The proteins dissolved in a $\mathrm{NaCl}$ containing solvent can bind ions to an extent determined by the protein properties. The presence of 'free' sodium and chloride ions can be detected by making use of the eutectic nature of the $\mathrm{NaCl}-\mathrm{H}_{2} \mathrm{O}$ system. The eutectic phase formed from the free salt ions, melts at $-21^{\circ} \mathrm{C}$ and produces an endotherm peak in the DSC curve. Fig. 3 shows that the DSC curves for pure water and for the full p53 TAD at two concentrations $\left(25 \mathrm{mg} / \mathrm{cm}^{3}\right.$ and $\left.12.5 \mathrm{mg} / \mathrm{cm}^{3}\right)$ dissolved in the buffer solution of $150 \mathrm{mM} \mathrm{NaCl}$, are clearly different. The low protein concentration was not sufficient to bind all salt
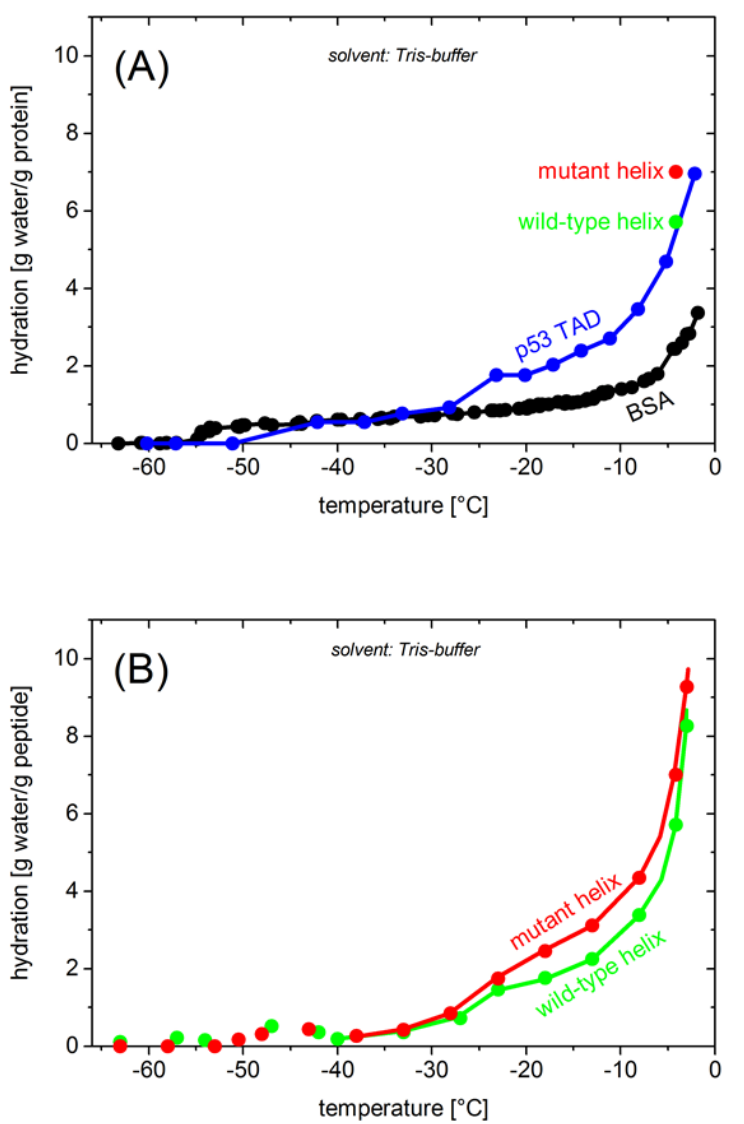

Fig. 2. Hydration measured by the ${ }^{1} \mathrm{H}-\mathrm{NMR}$ signal intensities of the mobile water for (A) $50 \mathrm{mg} / \mathrm{ml}$ p53 TAD (blue circles) and $50 \mathrm{mg} / \mathrm{ml}$ BSA (black circles) dissolved in Tris-buffer. The $T=$ $-4^{\circ} \mathrm{C}$ data for the helix peptides (green and red circles) are the same as in graph (B). (B) $30 \mathrm{mg} / \mathrm{ml}$ wild type p53 TAD helix peptide (green circles) and $30 \mathrm{mg} / \mathrm{ml}$ mutant helix peptide (red circles) dissolved in Tris-buffer; alternately, the hydration given in units of mole mobile water per mole peptide. Tris-buffer: 150 $\mathrm{mM} \mathrm{NaCl}, 50 \mathrm{mM}$ Tris, $1 \mathrm{mM}$ EDTA, $\mathrm{pH}$ 7.5. The lines are guides to the eye. 


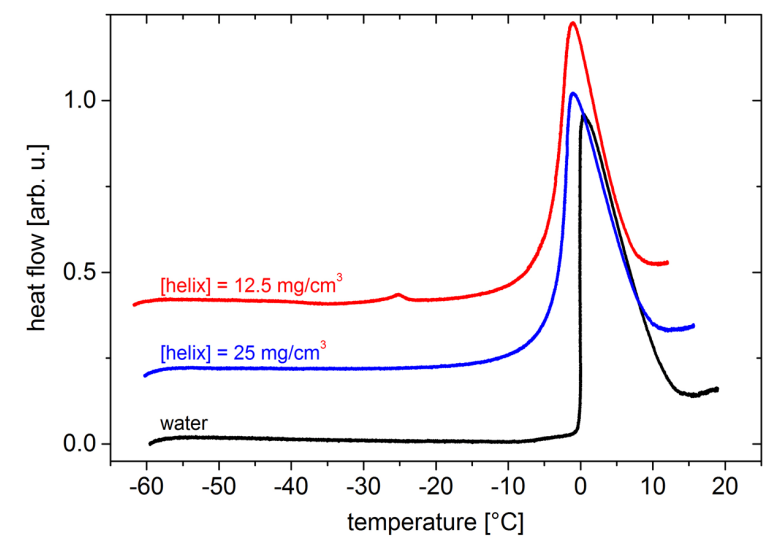

Fig. 3. DSC curves measured in double-distilled water (black line), wild type helix peptide (residues 15-29 of p53 TAD) of concentrations $25 \mathrm{mg} / \mathrm{cm}^{3}$ (blue line) and $12.5 \mathrm{mg} / \mathrm{cm}^{3}$ (red line) dissolved in Tris-buffer $(150 \mathrm{mM} \mathrm{NaCl}, 50 \mathrm{mM}$ Tris, $1 \mathrm{mM}$ EDTA, pH 7.5). The endotherm peak at $-25^{\circ} \mathrm{C}$ (red line) represents the melting of the eutectic phase formed by that fraction of the $\mathrm{NaCl}$ which was not bound by the peptide.

ions present, and the thermal effect of the eutectic melting was visible in the DSC curve (red line in Fig. 3). Earlier results show that the enthalpy changes caused by a phase transition could be studied as a function of the protein concentration in order to get information on the salt binding capacities of the proteins (Fig. 4). We found that the mutant peptide without a helix-forming propensity binds approximately two times more salt $\left(12.5 \mathrm{mg} / \mathrm{cm}^{3}\right.$ mutant peptide bound $\left.150 \mathrm{mM} \mathrm{NaCl}\right)$ than p53 TAD $\left(\sim 20 \mathrm{mg} / \mathrm{cm}^{3}\right.$ protein bound $\left.150 \mathrm{mM} \mathrm{NaCl}\right)$ or the wild type peptide $\left(21.9 \mathrm{mg} / \mathrm{cm}^{3}\right.$ peptide bound $150 \mathrm{mM}$ $\mathrm{NaCl}$ ). As observed, the wild type peptide bound the least amount of salt, the full p53 TAD somewhat more salt, and the mutant peptide bound the maximum amount of $\mathrm{NaCl}$.

\section{MATERIALS AND METHODS}

\section{Protein and peptide preparation}

The full-length p53 TAD (1-73) was expressed and purified, as described previously (7). The p53 helix peptide (15-29) and its mutant peptide with helix-breaking mutations $(19 \mathrm{~F} \rightarrow$ Ala, $22 \mathrm{~L} \rightarrow$ Ala, $23 \mathrm{~W} \rightarrow$ Ala, and $25 \mathrm{~L} \rightarrow \mathrm{Ala}$ ) were synthesized by a solid phase method with Multiple Peptide Synthesizer APEX $348 \Omega$ (Advanced Chemtech). Synthesized p53 TAD peptides contain the following amino acid sequences: a wild type peptide $=\left(\right.$ SQETFSDLWKLLPEN-NH $\left.{ }_{2}\right)$, and a mutant peptide $=$ (SQETASDAAKLAPEN-NH ${ }_{2}$ ). The C-termini of all the synthesized peptides were amidated. The peptides were purified by HPLC using Vydac $\mathrm{C}_{18}$ columns, and their masses confirmed by MALDI-TOF mass spectrometry.

\section{Wide-line NMR}

The aqueous protein solutions were prepared by dissolving the

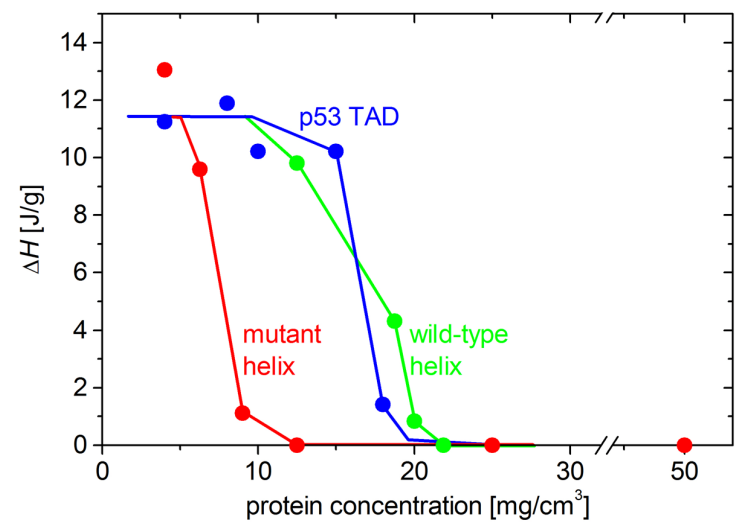

Fig. 4. Enthalpy changes associated with the eutectic melting of the $\mathrm{H}_{2} \mathrm{O}-\mathrm{NaCl}$ system measured as a function of protein concentration for full p53 TAD (blue squares), wild type p53 TAD helix peptide (green circles) and mutant peptide (red circle) dissolved in the buffer solution of $150 \mathrm{mM} \mathrm{NaCl}, 50 \mathrm{mM}$ Tris, 1 $\mathrm{mM}$ EDTA, $\mathrm{pH}$ 7.5. The lines are guides to the eye.

appropriate amounts of bovine serum albumin (BSA, Sigma) or p53TAD, and p53 helices in double-distilled water. Detailed descriptions of the applied NMR methods were reported earlier $(12,16)$. Briefly, the intensity of NMR signal is measured as the amplitude of free induction decay (FID) signal, extrapolated to $t=0$. The extrapolated amplitude is proportional to the number of contributing nuclei. In a multi-fraction system, the number of existing protons can be measured in a given phase, especially when in the mobile state. The measurements were done on cooled and reheated samples, in the temperature range of $-70^{\circ} \mathrm{C}$ to $+30^{\circ} \mathrm{C}$. All the protons were in a mobile state (water molecules in liquid state) above $0^{\circ} \mathrm{C}$, and the NMR intensities were normalized to this value. The effect of freezing on the protein solutions was controlled by the comparison of NMR parameters obtained before and after a freeze-thaw cycle, at temperatures above $0^{\circ} \mathrm{C}$. We observed that the freeze-thaw cycle causes no observable changes for the studied protein solutions as far as the measured NMR parameters are concerned.

Temperature was controlled by an open-cycle Janis cryostat with an uncertainty better than $\pm 1 \mathrm{~K} .{ }^{1} \mathrm{H}$ NMR measurements and data acquisition were accomplished by a Bruker AVANCE III NMR spectrometer at a frequency of $82.4 \mathrm{MHz}$, with a stability better than $\pm 10^{-6}$. The data points in the figures are based on spectra recorded by averaging signals to reach a signal-to-noise ratio better than 50 . We varied the number of averaged NMR signals to achieve the desired signal quantity for each sample and unfrozen water. The extrapolation to zero time was done by fitting a stretched exponential.

\section{Differential scanning calorimetry (DSC)}

Double-distilled water was used as a starting material and measured to obtain calibration data and parameters for 
temperature correction. We used $10 \mu \mathrm{l}$ of liquid in DSC measurements, and $70 \mu \mathrm{l}$ for NMR. The DSC results presented here were temperature corrected, the details of which and the enthalpy calculations are given elsewhere $(10,17)$. The DSC measurements were carried out at a heating rate of $q=2 \mathrm{~K}$ $\min ^{-1}$ on a home-built heat-flux differential scanning calorimeter (DSC). Prior to the experiment, the samples were cooled down at the same rate of $2 \mathrm{~K} \mathrm{~min}^{-1}$.

\section{DISCUSSION AND CONCLUSIONS}

The strengths of the water-protein interactions for IDPs vary in a narrow range, and are nearer to the bulk-phase water-water interactions than that for globular proteins (e.g. BSA). The "surface" of IDPs is more open to the water, and the amount of the bound water molecules involved is much greater than globular proteins. The number of the interacting protein-water connections were quantified, and the differences found are apparent for p53 TAD and the peptides (Figs. 1 and 2). The wild-type p53 TAD has a highly disordered structure as compared to BSA, a reference globular-protein. The degree of disorder (being less structured) known at the time when we set up this investigation increases in the following order: BSA $<$ wild type full p53 TAD $<$ wild type p53 TAD helix peptide $<$ mutant p53 TAD peptide. Our results are in agreement with this order. The DSC measurements apprise about the interactions of the proteins with the other solutes, especially with sodium and chloride ions. The number of bound ions can be calculated from the experimental DSC curves. The full p53 TAD and the peptides bound a considerably greater amount of $\mathrm{NaCl}$ than the globular BSA, in accordance with the earlier results. Based on the current results, we conclude that both methods, wide-line ${ }^{1} \mathrm{H}-\mathrm{NMR}$ and DSC, are not only capable of distinguishing IDPs against globular proteins but are also able to differentiate two structural states of IDPs, the MU (wild type p53 TAD peptide containing a helix PreSMo) and the CU (mutant p53 TAD peptide with helix-breaking mutations), in terms of their interactions with water molecules or other chemical entities, such as salt ions.

\section{ACKNOWLEDGEMENTS}

This work was supported by the Janos Bolyai Research Scholarship of the Hungarian Academy of Sciences (to TA) and by a Korea-Hungary Joint Lab Program from National Research Council of Science and Technology (NST) (NTC2251422) of Korea (to PT and $\mathrm{KH}$ ).

\section{REFERENCES}

1. Lee SH, Kim DH, Han JJ et al (2012) Understanding pre-structured motifs (PreSMos) in intrinsically unfolded proteins. Curr Protein Pept Sci 13, 34-54

2. Dunker AK, Lawson JD, Brown CJ et al (2001) Intrinsically disordered protein. J Mol Graph Model 19, 26-59

3. Uversky VN, Olefiled CJ and Dunker AK (2008) Intrinsically disordered proteins in human diseases: Introducing the D2 concept. Annu Rev Biophys 37, 215-246

4. Dunker AK, Obradovic Z, Romero P, Garner EC and Brown CJ (2000) Intrinsic protein disorder in complete genomes. Genome Inform 11, 161-171

5. Obradovic Z, Peng K, Vucetic S, Radivojac P and Dunker AK (2005) Exploiting heterogeneous sequence properties improves prediction of protein disorder. PROTEINS: Structure, Function, and Bioinformatics Suppl 7, 176-182

6. Bax A and Grzesiek S (1993) Methodological advances in protein NMR. Acc Chem Res 26, 131-138

7. Clore G and Gronenborn A (1991) Structures of larger proteins in solution: Three- and four-dimensional heteronuclear NMR spectroscopy. Science 252, 1390-1399

8. Lee $\mathrm{H}$, Mok KH, Muhandiram $\mathrm{R}$ et al (2000) Local structural elements in the mostly unstructured transcriptional activation domain of human p53. J Biol Chem 275, 29426-29432

9. Fuxreiter M, Simon I, Friedrich P and Tompa P (2004) Preformed structural elements feature in partner recognition by intrinsically unstructured proteins. J Mol Biol 338, 1015-1026

10. Tompa K, Banki P, Bokor M, Kamasa P, Lasanda G and Tompa P (2009) Interfacial water at protein surfaces: wide-line NMR and DSC characterization of hydration in ubiquitin solutions. Biophys J 96, 2789-2798

11. Hazy E, Bokor M, Kalmar L et al (2011) Distinct hydration properties of wild-type and familial point mutant A53T of alpha-Synuclein associated with Parkinson's disease. Biophys J 101, 2260-2266

12. Tompa K, Bokor M and Tompa P (2012) Wide-line NMR and protein hydration in intrinsically disordered protein analysis. Uversky VN, Dunker AK(eds.),167-196, Humana Press

13. Coke R and Kuntz ID (1974) The properties of water in biological systems. Annu Rev Biophys Bioeng 3, 95-126

14. Tompa K, Bokor M and Tompa P (2010) Hydration of intrinsically disordered proteins from wide-line NMR : In instrumental analysis of intrinsically disordered proteins: assessing structure and conformation. Uversky VN, Longhi S (eds.), 345-368, John Wiley \& Sons Inc

15. Kamasa P, Bokor M, Pyda M and Tompa K (2007) DSC approach for the investigation of mobile water fractions in aqueous solutions of $\mathrm{NaCl}$ and Tris buffer. Thermochimica Acta 464, 29-34

16. Tompa K, Banki P, Bokor M, Kamasa P, Lasanda G and Tompa P (2009) Interfacial water at protein surfaces: wide-line NMR and DSC characterization of hydration in ubiquitin solutions. Biophys J 96, 2789-2798

17. Tompa P, Banki $P$, Bokor $M$ et al (2006) Protein-water and protein- buffer interactions in the aqueous solution of an intrinsically unstructured plant dehydrin: NMR intensity and DSC aspects. Biophys J 91, 2243-2249

18. Tompa K, Bokor M, Verebélyi T and Tompa P (2015) Rotation barriers on protein molecular surfaces. Chem Phys 448, 15-25 